This is a self-archived version of an original article. This version may differ from the original in pagination and typographic details.

Author(s): Hämäläinen, Antti

Title: Responses to vulnerability : care ethics and the technologisation of eldercare

Year: 2020

Version: Accepted version (Final draft)

Copyright: @ Policy Press, 2020

Rights: In Copyright

Rights url: http://rightsstatements.org/page/lnC/1.0/?language=en

Please cite the original version:

Hämäläinen, A. (2020). Responses to vulnerability : care ethics and the technologisation of eldercare. International Journal of Care and Caring, 4(2), 167-182.

https://doi.org/10.1332/239788220X15833753877589 


\title{
Responses to vulnerability - care ethics and the technologisation of eldercare
}

Please do not cite this text! Cite only the version that will be published by International Journal of Care and Caring in 2020, DOI: https://doi.org/10.1332/239788220X15833753877589, found at https://www.ingentaconnect.com/content/tpp/ijcc/pre-prints/content-ijccd1900054.

Antti Hämäläinen, M.Soc.Sc.

Doctoral Student

Centre of Excellence in Research on Ageing and Care

University of Jyväskylä, Department of Social Sciences and Philosophy

antti.ap.hamalainen@jyu.fi

https://twitter.com/anttihamalainen

\begin{abstract}
$\underline{\text { Abstract }}$
This article argues for a reconceptualisation of care relations and uses the reconceptualisation to scrutinise the way technology is adopted in eldercare practices. First, it draws on the definition of care as attentiveness to vulnerability, used in the tradition of care ethics. Second, it specifies four essential aspects of care relations: relationality, dyadic mutuality, corporeality and devotion. Third, using socio-technical and phenomenological perspectives, care relations are contrasted with the idea of intertwining technological and human actors in care practices. Finally, using two adaptations of telecare as examples, the essential aspects of care relations are shown to be crucial for a thorough socio-technical understanding of eldercare and technology.
\end{abstract}

Keywords: care ethics, eldercare technologisation, phenomenology, STS

\section{Introduction}

A first stage in considering the role of new technologies in care practices requires thorough work to clarify some essential aspects of care relations. Instead of aiming for an exhaustive definition of caring, I identify certain elements of its immediate interpersonality, with the help of care ethics, social ontology and phenomenology. These conceptual moves are made to strengthen the argument that the special characteristics of care should be emphasised over more technocratic and economic views concerning care policy (Wærness, 1984b; Gilligan, 1982; Tronto, 2013).

After exploring essential aspects of care relations, I look at the role of technologies in eldercare arrangements using also ideas related to Social Studies of Science and Technology (STS), where the equivocality with regard to what is human and what is technological in a given practice is brought to the fore (eg. Latour and Woolgar, 1986). This approach offers an understanding of technology as an integral part of care arrangements (and vice versa).

Eldercare provides an important context in which to consider these assumptions. New 
technologies have played a pioneering role in eldercare in Western societies, yet older people as end-users have been neglected in design processes (Östlund et al, 2015). While central reasons for the technologisation of eldercare seem to revolve around challenges involving the economic resourcing of ageing populations, the impacts of technologisation on the characteristics of care also require serious attention. Eldercare is also contextually important on account of vulnerability. Old age increases the probability of requiring care, which, at the same time, exposes the vulnerability we face regarding our existence. Ageing forces us to consider the boundaries of our being, the fact that none of us can escape harm, and therefore that we all rely on other people's help.

This article seeks answers to two conceptual questions: (1) what is specific to interpersonal care relations, and (2) what does this specificity mean when adopting new technologies in eldercare practices? In the first section, the tradition of care ethics is briefly introduced and care is framed around the concept of vulnerability. The second section scrutinises the four essential aspects of interpersonal care relations, the first of which is relationality, a concept found in the literature on care ethics. The second aspect is dyadic mutuality, which is considered crucial in terms of the relational stance. In a third aspect, care relations are considered in terms of corporeality, whereby caring is tied to concrete, embodied interactions. The fourth aspect explores the ethical obligation of care relations in terms of devotion. In order to analyse how technology is situated in care relations, the third section of the article contrasts care ethics with perspectives of socio-technicality and explores the impacts of two telecare technologies on eldercare practices, ultimately clarifying the analytical potential of the theoretical framework established in the second section of the article. The final section presents the article's concluding remarks on the technologisation of eldercare.

\section{Care ethics as a philosophy of vulnerability}

In the 1970s and 1980s, "second-wave feminism" established with it a relational moral philosophy called care ethics, which has recently undergone a growth in popularity (Hamington, 2018: 312). Care ethicists contrast their thinking with Western, liberal moral philosophy by criticising its foundation in abstract formulations resulting in symmetrical actions made by atomistic rational actors (Gilligan, 1982; Noddings, 1984). According to Stephanie Collins' (2015) reading of the history of care ethics, care ethicists maintain that moral responsibility is situational in that moral deliberation is tied to the relations between particular people with unique histories rather than to abstract principles. In her summary, care ethics also holds that the particular needs of vulnerable individuals need to be the focus of moral attention rather than the universal rights of rational agents. Care ethics also views moral deliberation as an ongoing process, rather than as detached acts or reciprocal calculations, and considers that the actions and attitudes involved in active caring for another being are needed rather than, or at least in addition to, mere noninterference (Collins, 2015: 5). Therefore, while 'care' has been multifacetedly used as a philosophical concept also before care ethics, I view and develop it in concert with the perspectives of care ethics introduced in the past four decades - in broad terms, as a response to the need of another being. 
Care ethicists have argued that dependency is an essential aspect of care, in that becoming a person inexorably involves receiving some sort of care. Sarah Clark Miller (2005) writes:

[...] persons are not fundamentally independent. Rather, they are mutually dependent. Our unavoidable dependency means that if we are to survive, let alone thrive in leading lives that are recognizably human, others must respond to our dependent selves by meeting our needs through their caring actions. During certain life moments, failure on the part of others to do so could amount to our demise. But I am not solely a dependent being who needs others to bolster my wellbeing; others, in their inevitable dependence, also need my assistance, hence solidifying the mutuality of the relation. (Miller, 2005: 140-141).

In this vein, the mutuality and reciprocity involved in relating to the interdependence between oneself and another similar being form the ethical basis of care. Every human being has entered the world completely helpless and will experience periods of helplessness during their life course, during which being human is considered to be conditioned by a dependence on others (Kittay, 1999; Held, 2006; Tronto, 2013).

Daniel Engster (2018) has recently argued that care ethics should view dependency as subordinate to vulnerability. While care constitutes the addressing of explicit human dependency par excellence, a broader concept of vulnerability is fruitful in emphasising the fact that we are all vulnerable to unwanted ailments, injuries, diseases, and so forth - and therefore to a potential dependence on others - throughout our life course. An emphasis on "unwanted" is crucial, in that vulnerability does not always appear in negative forms. Sometimes choosing to make oneself vulnerable is necessary in order to build close relationships with others, or in terms of other enriching aspects of our lives (Engster, 2018: 7).

While there is a broad discussion on vulnerability and care (see MacKenzie et al, 2013), at this point it suffices to support Engster's view with some notions of phenomenology, where vulnerability is thought to stem from the tacit understanding of our existence as something limited by death. Being human is always being-at-risk, due to the possibility of being violated. This may involve violation by the other, in terms of neglect or violence, or may involve one's own suffering and death (Coeckelbergh, 2013). Vulnerability of this magnitude bases care ethics better than (only) the situational dependence on others. Therefore, human vulnerability is not a stable concept. It resides in neither the subject nor the object - neither within us nor 'out there'. It is defined instead by the fluid relations between the subject and the object. Humans become vulnerable by acting in relation to others and the world around them (Coeckelbergh, 2013: 43-45).

Based on the above, one of the core arguments of care ethics would seem to be that care relations are very special existential loci, because they are precisely where vulnerability is addressed (or left unaddressed). I take this as the point of departure for the further exploration of interpersonal care relations. 


\section{What are the essential aspects of care relations?}

This section explores the aspects which can be considered to condition caring in terms of responding to vulnerability. It does not claim to cover everything involved in caring, but rather seeks what should be regarded as, at the very least, the essential aspects of immediate care relations. These features are presented as relationality, dyadic mutuality, corporeality and devotion.

First, however, it is necessary to clarify what is meant here by 'essentiality', especially as its gendered definition was explicitly abandoned in care ethics a long time ago (Tronto, 1993; Kittay, 1999). While essentiality will be clarified in the process of exploring the different aspects of care, at this point it is best defined as something that refers to ontology. Examples of ontological assumptions in care ethics are, for example, that dependency and relationality are fundamental to the human condition. Here, the ontological in terms of care relations refers to the culturally stable aspects of human interrelatedness - to the way we have come to exist in relation to one another and to the world through care. Importantly, the essentiality of the characteristics of care relations does not mean metaphysical essentiality, but rather the conceptual stability resulting from the historical depth of these characteristics. For instance, technology has been part of our being since stones were made into tools and fire was mastered, meaning that it has been embedded into our experience and our traditions for so long that being itself cannot be construed without it (Stiegler, 1998). Similarly, our immediate relationship to another sentient and vulnerable being, distinguished from other forms of being, has been built into the way we relate to the world for at least as long as technology in the aforementioned sense. This interpretation of essentiality is important in that the exploration of care phenomena, such as different forms of technologisation, also requires some emphasis on the depth of the relations at the core of caring.

\section{The relationality of vulnerability}

The first essential aspect of interpersonal care relations is relationality, one of the conceptual cornerstones in the tradition of care ethics. Joan Tronto writes:

To care well requires the recognition that care is relational: no judgment about whether care is good can be accomplished from a singular perspective, not that of caregivers or care receivers. (Tronto, 2013: 140)

This relational stance is thought to be in conflict with modernist moral philosophies that seek universal moral guidelines in order to overcome the relational aspects of morality (Wilshire, 1992; Hekman, 1995). In care ethics, interdependency is morally emphasised over independency in that caring is situated within the relational co-existence between people, not only as the deliberation of self-sufficient individuals (Held, 2006). Presenting agency as fluid means that ongoing and situational relationships can transcend dull categorisations such as 'consumers', 'care receivers' or 'older people', and seek instead the moral essence in the particularities of each interaction (Hill and Thomson, 2017: 179). Care 
interactions draw attention to vulnerabilities we all share, but which are manifested in unique ways, for they always involve different people with differing histories.

In the aforementioned sense, situationality and temporality are at the core of the relational, ethico-ontological understanding of care ethics. Care ethicists' views on relationality have partly referred to the complex social, economic and political relations that organise, facilitate and hinder caring. The focus has therefore often been on culturally constructed phenomena, for example on the perspectives of gender and labour, and rightly so, for caring is historically gendered and has remained on the margins of Western moral philosophy. This academic marginalisation is no surprise, as those involved in caring, predominantly women, have also been socially marginalised by patriarchy, rendering care an invisible form of labour (Gilligan, 1982; Tronto, 1993). In short, along with exploring the essential "nature" of caring, it is also important to regard the dangers of essentialisations, in that they can (and evidently have) lead to unequal caring responsibilities. These perspectives provide a good definition of the historically polarised aspects of care, and have been explored thoroughly for example in Tronto's Caring Democracy (2013).

While each caring event is inevitably affected by the aforementioned cultural relationalities, my aim is to explore the more immediate life-world of particular caring events. This approach benefits from a more narrow definition of relationality, the repercussions of which are further explicated in the next subsection concerning dyadicity. Generally, however, this means steering away from political theorisations of care towards a more phenomenological perspective. I agree with the view that the explanatory force of care ethics in many cases resides exactly in combining these two perspectives (Barnes, 2012: 33-34; Tronto, 2013), however, discussing the impacts of the current and future use of technology on care relations at the end of this article proves more powerful if the phenomenological aspects are emphasised. Of course, this perspective does not neglect the political theorisations altogether, in that they include views, such as vulnerability, relationality and corporeality, that are central for this article's purpose of exploring the impact of technology on care relations.

Thus in this article, the narrower definition of relationality points to the situational and temporal character of the experiences of particular persons - to their life history, habits, needs and so forth - which require caring attention, rather than to broader interrelations consisting of, for example, social, political and economic networks. The focus is thus on each event of caring, each relation at hand, not on the abundance of relations that facilitate or structure it. To further focus this view, the article next considers dyadicity as the second essential aspect of care relations, one which has been extensively discussed in care theories over recent decades but still seems to require attention in discussions of care.

\section{Dyadic mutuality frames care as relating to the vulnerability of a self-reflecting other}

In care ethics, dyadic relations have often been transcended in order to broaden the scope to cover institutions, for instance (Tronto, 2013; Robinson 1999). I agree with Marian 
Barnes (2015) who explores the problems with regard to dyadicity by pointing out that, along with intimate face-to-face interactions, more spatially and temporally distant actions also constitute care. For example, to some extent, one can be attentive to another person's need from a distance by, for instance, helping someone with an application crucial for receiving a particular care service, or comforting someone over the internet.

First, however, spatial or temporal distance does not really change the dyadic characteristic of such care settings, in that ultimately all manifestations of care can be traced to someone's situational attentiveness to a particular vulnerability. Along with relations in their networked sense, ultimately someone's attentiveness to particularity is required. Second, Diedrich et al (2006) have highlighted the broader problem with regard to how caring is situated in the immediate second-person relations and politico-structural third-person relations. Based on Emmanuel Lévinas' work, the authors note that our immediate, second-person relation to another person cannot take all our caring attention, as it is not the only relation we find ourselves in. Other, practically unlimited and therefore endlessly complex third-person relations constitute the political phenomena addressed, for example when care ethicists explore relationality in its broader definition (Diedrich et al, 2006: 45-50; Lévinas, 1969). The attentiveness to another's need is always limited by other relations. However, and importantly for the argument on dyadicity, this does not mean that the specific essence of second-person attentiveness should not be regarded as the primary departure point of caring, which is why it is regarded here as an aspect without which caring would not be caring. As Lévinas says:

The interpersonal relation I establish with the Other, I must also establish with other men; there is thus a necessity to moderate this privilege of the Other; from whence comes justice. Justice, exercised through institutions, which are inevitable, must always be held in check by the initial interpersonal relation. (Lévinas \& Nemo, 1985: 90).

Of course, dyadicity in itself does not suffice, which is why the perspectives on corporeality and devotion are needed (discussed later), but if the dyadic aspect were left out, the aforementioned examples of caring would make little sense. Concerning the example of comforting someone over the Internet, we would then have to accept that an online algorithm would suffice as a caregiver. If caring was not defined as a distinctive relation to a certain, concrete other, from someone to someone, the scrutiny of what is immediate in care relations would become abstract. Therefore, in the centre of the argument on dyadicity is that, ideally, one cannot care attentively for an imaginary other, or a number of people at the same time (or vice versa), because the ability to relate to the situational vulnerability of the other will be fragmented and diminished, at the very least.

For a reader who is yet not certain that an algorithm could not provide care, I will further clarify the interpersonal basis of dyadicity. This dyadic interpretation of care not only involves attentiveness towards particular personal features and situations - i.e. relationality as it is defined in this article - but also the definitively mutual aspect of it. Here, the intertwinement of the uniqueness and the similarity of the other is presented as an aspect of dyadic mutuality. While the next subsection will further explore the corporeal aspects and the fourth one the ethical obligation related to care, first, relationality is connected to dyadicity by theories of recognition. Here, recognition does not mean 
colloquial "acknowledgement of" or "distinguishing" an entity, but rather the intersubjective basis for human self-relations. Based on G. W. F. Hegel, theories of recognition define self-consciousness as fundamentally social, as recognition takes place only within a recognition-relationship to another self-consciousness (Hegel, 1977). A person can thus experience her/himself as needy and desiring only within a recognitionrelationship to another person which, reciprocally, is possible by recognising another being with similar needs (Honneth, 1995: 37). Through recognition, people exist in relation to themselves and their environment partly from the viewpoint of another being (Laitinen, Särkelä and Ikäheimo, 2015: 3). Rather than a means to an end (an object), then, through recognition the other becomes an end in itself.

Axel Honneth (1995) has steered away from Hegel's metaphysical theorisation by connecting recognition to the beginning of human life. The first steps towards recognition are taken when an infant separates her/himself from her/his mother ontologically and becomes self-relational (Honneth, 1995: 98-100). Later on in life, this relationality defines friendship, love and the ability to care. In this way, recognition provides a foundation for the desire to merge with the other by experiencing the other as another consciousness who re-establishes her/his ontological boundary, leading to a "mutual dissolution of boundaries" (Honneth, 1995: 104-105). The gendered presumptions of the mother-child dyad as the basis of care are well known and belong in the past, and I do not attempt to revive this sort of dyadicity as a fundamental argument for caring. Rather, the ontological and socio-psychological arguments of recognition theory work together here in systematising human relationality and vulnerability on a general level. In theories of recognition, the ability of self-relation is tied to mutual similarity, thus also making it possible to recognise the unique individuality of the other.

By arguing "beyond dyadicity", some care ethicists have broadened the conceptual scope of care and made visible its explanatory power in exploring areas such as international relations (Robinson, 1999) or democracy (Tronto, 2013). I argue that re-emphasising dyadicity may have great explanatory potential in other key areas, such as the immediate life-world of eldercare relations directly impacted by technologisation. Also, transcending dyadicity to the extent of defining care as potentially covering non-sentient objects in the world (Tronto, 1993: 100-108) can be problematic in that caring is therefore detached from the ability to self-reflect and to be attentive to the self-reflection of another similar(ly unique) being. My worry is that something essential with regard to caring may be lost in the process. Again, I do not claim that the temporal and spatial arrangements where the caring happens do not involve a whole range of economic, political or sociotechnical factors. I claim that the distinct and precious character of the activity and disposition called care resides somewhere beneath such contingencies. Caring actualises as part of networks of relations (what phenomenon would not?), however, it is not those networks but rather something that would seem empty without keeping the primary attentiveness to a similarly vulnerable, particular other at the heart of scrutiny.

Before considering the technologisation of eldercare from these theoretical perspectives, relationality and dyadic mutuality need to be placed in the context of the lived world experienced through human bodies. Therefore, an aspect of corporeality is required. 


\section{Corporeality situates vulnerability in an affectual life-world of embodied beings}

Care professionals are skilled in interpreting situational needs by gestures, postures and expressions (Twigg, 2000), as presence and touch can mediate a good deal of information on experience, intentions, wishes, emotions and general well-being (Turkle, 2011). According to Twigg (2000), corporeality, which has been a neglected area throughout the course of Western philosophy as well as in gerontology, provides an antithesis to the rationalism of enlightenment defined by logical reasoning, control and abstraction, which have marginalised the role of the body and feelings in defining human being. Twigg also connects this to neoliberal and managerialist care practices which leave no room for corporeal existence (Twgg, 2000: 8-9). Corporeality is especially important in terms of ageing, as physical abilities start to wane at the end of life. However, even in the tendency towards the 'sociology of the body' during recent decades, ageing has surprisingly been an almost completely neglected area (Gilleard and Higgs, 2013: 3-4; Twigg, 2000: 7).

As Maurice Hamington claims in Embodied Care (2004), the corporeal relationship to another human being is the foundation for the very potential to care:

"[...] care denotes an approach to personal and social morality that shifts ethical considerations to context, relationships, and affective knowledge in a manner that can be fully understood only if care's embodied dimension is recognized." (Hamington, 2004: 3)

He argues that understanding the other manifests itself in small or unnoticeable gestures, smells, sounds, etc., which bypass our rational and conscious abilities. These nevertheless affect all human interaction, and are thus a constituent aspect of caring and fundamental in analysing care relations (Hamington, 2004: 48). Intentions are not by essence hidden within us until they are expressed as propositions. Instead, they are expressed in embodied action (however subtle) perceptible to others, and thus also as something that can be changed through the process of interacting (Fuchs and De Jaegher, 2009: 469).

Introducing the aspect of corporeality strengthens the argument that vulnerability is at the core of care relations, in that human needs, whether physical or existential, are corporeal in essence. This also noticeably strengthens the argument on the relationality and dyadic mutuality of care ethics by providing these abstractions within the context of a corporeal, inter-related life-world. Fuchs and De Jaegher (2009: 465) write about mutual incorporation as "a process in which the lived bodies of both participants extend and form a common intercorporeality". This mutuality is the practical inter-relatedness manifest in embodied practices, as noted by Fuchs and De Jaegher (2009: 472) who write that coexistence in a "dyadic bodily state" mediated through intentional perception, gestures, voices and touch, allows an empathic disposition towards another person. It also suggests that the dynamic, intentional and embodied interplay between "two centres of gravity" creates an in-between where the meaning of the situation at hand and the self-relation of embodied actors are co-created (Fuchs and De Jaegher, 2009: 472-476). An embodied perception of the other (in terms of both perceiving the other and the other's perception) thus defines self-relation through-and-through. This is expressed in a similar way by recognition theorists, but is here rooted more firmly in the lived world of embodied 
existence. Borrowing from Hamington, the potential to care is born in the corporeal co-creation of meaning (Hamington, 2004: 5).

Next, it is argued that, along with relationality, dyadic mutuality and corporeality, a scrutiny of care relations also calls for an aspect of devotion, which completes this article's conceptualisation as not simply a descriptive but rather an ethical one.

\section{Demanding reactions: care as devotion}

So far in this article, the essential aspects of care relations have been presented as ones which allow for the possibility of being attentive to the vulnerability of the other. Without relationality and dyadicity, the situatedness and uniqueness of vulnerability would be lost, and without corporeality it would have no affectual world in which to reside. While these aspects provide the potential for responsibility, exploring the obligation for its practical manifestation as the response to the profound vulnerability of the other is still required. Ethical questions arising from this ontology, such as 'what ought I to do' or 'why should one care', still need to be presented with caution.

In care ethics, caring is based on both attentiveness and the action which results from it. In Marian Barnes' words, "without action to follow the awareness of need, care cannot be complete" (Barnes, 2012: 21). Following Joan Tronto (1993) and Daniel Engster (2007), Barnes calls this "responsibility" or "obligation" (Barnes, 2012: 21-23). Viewing responsibility as something that expands care into an argument on its democratic potential (Tronto 2013, 50-57) includes an indispensable view on the place of care in societies obsessed by economic production. For my purpose of exploring the more immediate second-person aspects of caring, however, the perspective of ethical obligation must remain at the level of intercorporeal and dyadic settings between historically unique, concrete beings. To distinguish the aforementioned perspectives on responsibility and obligation from what follows, the responsibility related to caring is here named devotion.

Paying attention to the intertwinement of the ontological and the ethical found in phenomenology can expand on recognition theories' views on the intersubjective basis of self-relation. First, in Lévinas' influential view, the face (or more broadly, the expression) of another being founds ethics, in that only there one can experience something that does not bend to one's will. It opens up an infinite unknown - it is not simply another person but otherness that is revealed, something that is beyond our cognitive or practical grasp. This preconditions ethics in that ultimately it is the naked vulnerability in the other's face that insists upon us not to inflict harm upon them. Analogously to recognition theory, and reaffirming my former arguments of dyadic mutuality and corporeality, this creates an ethical responsibility, because such awareness of otherness founds our own subjectivity as well: only the nakedness of the other's face reveals our own vulnerable existence (Lévinas 1969, 194-201).

Following Anne-Marie Søndergaard Christensen (2015), such an ethical perspective does not yet sufficiently explore how the ethical content in this relation could possibly be achieved. The obligation can be reaffirmed, however, with the help of Knud Ejler 
Løgstrup's (1997) notion on the ethical demand. Løgstrup's thinking rests on the phenomenological fact that we always-already find ourselves in the world, mixed up in relations and exposed to another people's will and mercy, meaning that we find ourselves in trusting relationships to each other. Relational ethics requires that trust is initially primary to mistrust, because we cannot act without, at least minimally, exposing ourselves to the power of other people (Løgstrup: 8-9).

The ethical demand follows from the fact of this basic trust because it forces us always to make a choice between either regarding the other's trust, i.e. taking care of another person's life, or to act in our own self-interest (Søndergaard Christensen, 2015: 27-8). In concert with this article's view on relationality and dyadicity, Søndergaard Christensen (2015: 30) writes:

When I am faced with the ethical demand, it returns me to the particular relation that exists between the other and me; it simply points out that I hold his or her particular life in my hand [emphasis in original].

It follows from this that, ideally, caring does not involve an expectation of receiving care in return. It also means that care can only be given and received but not demanded, for once care is demanded, it has to be demanded, which means that an articulated demand for care is already a response to someone's failure to respond to the ethical demand. Reacting to the vulnerability of the other thus cannot mean fulfilling every proposition he or she has made, nor can it mean only acting according to established social norms (Løgstrup, 1997). What is required instead is devotion to the other's practical situation and therefore interest in the particularity of their needs, habits, relationships, institutional positions, and so forth - ethical devotion to whatever particular relationalities constitute the other's life. The fifth essential aspect of care relations is thus devotion, the selfless and attentive response to the vulnerabilities of another similar(ly particular) being.

\section{Conclusion on the essential aspects of care relations}

To sum up the theoretical assumptions I have presented thus far, interpersonal care relations need to be regarded:

1. as relational, in the sense that attention needs to be placed on the uniqueness of a particular person's situation;

2. as a mutually dyadic relation between two, self-relational beings, without which the relational aspects of caring would be abstract;

3. as corporeally manifest in embodied gestures, a life-world which makes responding to vulnerability possible;

4. as ethical devotion, in the sense that if care had to be demanded or exchanged it would become merely contractual reciprocity rather than selfless attentiveness to the vulnerability of the other. 
However, essential as they are, interpersonal relations do not cover all of our worldly relations, which is why it is still important, in the final section of this article, to complete the argument by placing these relations in the context of care arrangements impacted by technologisation.

\section{Care ethics and the sociotechnical vulnerability transformations related to telecare}

The remaining sections explore some influences of technological responses on vulnerabilities in eldercare. Care technologies consist of a plethora of technical appliances and systems, and technologisation of eldercare is of course not simply a "current" or "new" advancement, given the history of walking sticks, wheelchairs or hearing aids. However, a characteristic of recent technological developments in care in the Western world is that they are seen as more systematic solutions to the economic burden caused by ageing populations (see e.g. Roberts and Mort, 2009). Eldercare has also been a testing ground for different technologies for decades, and older people have rarely had any input into these developments (Östlund et al, 2015).

Since the remaining space does not permit an extensive assessment of eldercare technologies, a set of conceptual insights is used to explore the impacts of two telecare technologies. The theoretical scope of this article requires, first, taking into account the sociotechnical interplay between human actors and technological artefacts. Rather than considering artefacts as simply practical objects with negative or positive uses, they can be thought of as entities which are deeply intertwined in care relations and practices, remoulding the human life-world, as has been argued in Social Studies of Science and Technology (STS) and other post-humanistic philosophy (see e.g. Latour and Woolgar, 1986; Latour, 2005; Mol, 2002;2008). This sociotechnical perspective cannot be avoided in exploring technology as an aspect of care relations.

Second, technology needs to be thought of as something that transforms certain vulnerabilities into other vulnerabilities. According to Coeckelbergh (2013), technology should be thought of as part of the ontology and ethics of vulnerability. Not only do we use technologies as tool-like extensions in interpersonal relations, but our use (and nonuse) of technologies also shapes our experiences, habits and therefore our care relations, depending on how the vulnerabilities are met. Technologies, as responses to vulnerability, have to be regarded as something which always transforms vulnerability - not as something that can reduce or rid us of vulnerabilities as modern scientific and technological praxis suggests (Coeckelbergh, 2013:4-5).

However, an ethical framework is also needed in order to analyse care practices in a meaningful way. The use of technology always-already includes an ethical aspect in that, by reshaping human practices, technologies "give material answers to ethical questions" (Verbeek, 2006). Therefore, third, a conceptual framework of care ethics is required to prevent a mere descriptive assessment of the pros and cons of technology use. Relationality, mutual dyadicity, corporeality and devotion become important in considering which vulnerabilities technology can address in eldercare, and at the same 
time which other vulnerabilities it creates in terms of the essential aspects of care. Next, this consideration forms the final content of this article.

Telecare for older people: why care ethics is needed in scrutinising sociotechnical care practices

Finally, the following two adaptations of telecare provide interesting examples of vulnerability transformations in terms of illustrating how the conceptualisation of care relations presented in this paper can be put to use when exploring practical phenomena related to eldercare.

First, telecare can refer to screen visits, as in video calls made by care professionals to homecare receivers, making care and nursing possible from a distance. With this technology, feelings of loneliness can be reduced in the sense that care receivers' social needs can be addressed through interactions which take account of their life-history (Van der Heide et al, 2012). In this light, screen visits respond to home-care receivers' vulnerability with regard to the lack of human interaction and to vulnerabilities related to memory disorders which hinder sufficient self-care, for instance. While we have become more and more accustomed to communicating via screens, compared to physical presence, a screen visit is inevitably a distorted presentation of both persons regardless of the video or audio resolutions. Among other things, this can lead to trivial vulnerabilities of miscommunication and misrecognition of needs.

When exploring how vulnerabilities are transformed by screen visits, it quickly becomes clear that some social vulnerabilities can be addressed, but that new vulnerabilities also emerge in terms of knowing how to use the devices, the quality of the contact and fewer visits. It is difficult to know which of the transformations caused by telecare in terms of vulnerability are, or would be, acceptable unless these sociotechnical practices are viewed through the essential aspects of care defined in this article.

Therefore, concerning relationality and screen visits in home care, time can potentially be released for care professionals to interact more meaningfully with care receivers, so that relational needs, such as the need for social interaction or being able to report urgent health issues, can be addressed. Addressing needs via screen visits happens dyadically, in that screen visits may focus care professionals' attention better upon one-on-one conversations. Therefore, screen visits do not seem to pose a great risk for the relational and dyadic aspects of caring, given that they are fully considered in the design processes. On the other hand, there is a danger of transforming caring interactions into more technical, monotonous and distant labour, thereby giving rise to new vulnerabilities regarding at least the aspect of relationality.

Concerning screen visits, a key aspect is of course corporeality in that it directly impacts all the other aspects of caring. Although screen visits are not non-corporeal in the sense that facial expressions, gestures and tones are involved in audio-visual interaction, they lack a human touch and the feeling that someone is actually there, with all the corporeal nuances that go with meeting someone in person. Touching is also central not only to 
caring, but also to clinical treatment (Lupton and Maslen, 2017). Anyone would agree that a key element in interaction is missing in a video call to a loved one, and this cannot be underestimated in arranging care. The more physically present caring is substituted with screen visits, the more the corporeal aspects of caring are lost.

Concerning screen visits, devotion is possible to a fair extent, within the limits of corporeality. In screen visits it is possible to notice changes in behaviour, gestures or other non-lingual aspects that facilitate devotion. However, neglecting the aspect of corporeal presence prevents care professionals from observing the whole situation, such as minor details in the whole apartment or comforting the home care recipient by corporeal gestures or touches. Going back to Lévinas' notion of the other's face (or corporeal expression) as something that awakens our ethical understanding, the faces presented on screens seem to lack something of this tension, thereby restraining the possibility of fully devotional caring action.

As for the second example, telecare can also refer to social alarms, as in bracelets or pendants worn by the persons receiving care, connecting them to care professionals by means of information technology. They have been introduced in home care or long-term care to make both care workers and older people feel safer, and to reduce "unnecessary" visits. Social alarms respond to certain vulnerabilities, such as the danger of not receiving help when it is needed in times of decreasing resources where the number of care workers has been reduced. They also make it possible for older persons with care needs to continue to live at home. However, social alarms have also led to new vulnerabilities which were difficult to anticipate when they were designed, i.e. what was prescribed to them (see Akrich and Latour, 1992; Pols and Willems, 2011). Some home care receivers are afraid to go out of the range of the alarm system in case they are unable to get help when they need it, so they no longer go out (Aceros et al, 2015; Stokke, 2017). Some older people also experience the stigma of having to wear items which visibly define them as dependent on care (Cook et al, 2016). Again, these vulnerability transformations seem hard to grasp without the essential aspects that highlight what caring is, or ought to be, about.

First, when social alarms are viewed through relationality and dyadic mutuality, the focus is on person-specific spatial, temporal, social and psychological needs. Assuming care receivers are recognised as holistic individuals with life histories and particular dispositions and desires, a notable transformation in vulnerability where social alarms are concerned involves binarising the expressions of care needs. If a person does not press a button, they can be taken to have no need for attention. For instance, cognitive disability could impede a person from fully realising what pressing a button on a bracelet means, and the continuous alarms could start to be seen as normal and thus not taken as seriously as they should be. Here, person-specific attentiveness is transformed into more binarised and structured care practices, thereby restricting the relational and dyadic aspects of caring.

When corporeality is explored with regard to social alarms, responses to needs differ from situations where care workers recognise and attend to care receivers' needs in person. Being physically present allows care workers to pay attention to gestures, smells, 
appearance, etc., and to be with clients just for the sake of being there, a corporeal area of care that cannot be disregarded. Of course, the alarms also lead to corporeal interactions, but by impacting on the expressing of older people's care needs, use of social alarms may lead to a reduced presence and thus less corporeally mediated care and attention.

In terms of devotion, binarising the expression of care needs into either having or not having a need for care, the responsibility seems to lie more with the person in need of care. Some social-alarm users have reported being uncertain about how to decide whether their own needs in particular situations are serious enough to call for help (Stokke, 2017: 10), which simply means that they do not receive the care they need due to the situation being prescribed by the technology. Of course, this contrasts heavily with active devotion as in holistic addressing of the vulnerability of the older person in need of care.

\section{Discussion}

In the light of the conceptual view presented in this paper, assessing certain historical manifestations of eldercare, such as applying telecare technologies in home care or longterm care settings, requires taking into account some essential aspects of care relations. The previous section highlighted that applying telecare as part of eldercare practices reshapes these essential aspects of caring in a number of ways. While the examples provided were limited, they have shown how the practicalities of caring can be viewed through such essentialisations, and that such an ethico-ontological perspective is needed in order to explore how caring may become transformed in complex and fluid sociotechnical settings.

The importance of one-on-one interaction is usually taken into consideration in political strategies involving care technology, but it often seems to be regarded as secondary to other aspects of arranging care. For instance, in telecare discourse in the UK, care work has been divided into monitoring, physical care and socio-emotional care (Roberts and Mort, 2009: 138). Once caring is split up like this, it is easier to make an argument for the increasing use of technologies which can only cover certain dimensions of caring. This article can be thought of as a point of departure for a (care) ethical scrutiny of care technologies, though the framework can also be used in other perspectives on care.

While the technologisation of eldercare also includes great benefits, the danger of eroding human relationships where care technologies are used is twofold: not only may there be less human contact but the nature of it may change as well (Baldwin, 2005). It is crucial that the relationships between the ones caring and the care recipients are not determined and mediated primarily by technology. Where technology determines care, there is a danger that morality (and other areas of life) will be determined primarily by what is technologically possible (Baldwin, 2005; Mackenzie and Wajcman, 1999). First, according to Baldwin (2005), this shift could mean that the main attention in care practices begins to focus on the technological devices and systems that have become central to caring, instead of care professionals focusing on the care recipient. Care recipients could also begin to be seen through the lens of technology, in that their existence could be mediated 
by systemic information, or diminishing physical and mental capability could be seen merely as accumulative stages of technological needs (Baldwin, 2005).

According to Verbeek (2006), technologies give material answers to ethical questions. Let us bear in mind that applying new technologies is not a purely technical matter - the habits, values and nature of caring actions are gradually transformed into something else when new technologies are applied. In physically, mentally and socially delicate eldercare settings, it is of great importance to explicitly recognise this delicate nature of caring, thereby focusing on the relational, dyadic, corporeal and devotional essence of responding to vulnerability alongside the demographic, economic and technical arguments.

\section{References}

Aceros, J.C., Pols, J. and Domènech, M. (2015) Where is grandma? Home telecare, good aging and the domestication of later life, Technological Forecasting \& Social Change, 93:102-11.

Akrich, M. and Latour, B. (1992) A summary of a convenient vocabulary for the semiotics of human and nonhuman assemblies, Cambridge, MA: The MIT Press.

Baldwin, G. (2005) Technology, dementia, and ethics: Rethinking the issues. Disability Studies Quarterly, 25(3).

Barnes, M. (2012) Care in everyday life: An ethic of care in practice, Chicago: Policy Press.

Barnes, M. (2015) Beyond the dyad: exploring the multidimensionality of care. In Barnes, M. and Brannelly, T. (eds) Ethics of care: Critical advances in international perspective, Bristol: The Policy Press.

Coeckelbergh, M. (2013) Human Being @ Risk. Enhancement, technology, and the evaluation of vulnerability transformations. Dordrecth: Springer.

Collins, S. (2015) Core of care ethics, Manchester: Macmillan.

Cook, E.J., Randhawa, G., Sharp, C., Ali, N., Guppy, A., Barton, G., Bateman, A. and Crawford-White J. (2016) Exploring the factors that influence the decision to adopt and engage with an integrated assistive telehealth and telecare service in Cambridgeshire, UK: a nested qualitative study of patient 'users' and 'non- users', BMC Health Services Research, 16(1):137.

Diedrich, W. W., Burggraeve, R. and Gastmans C. (2006) Towards a Levinasian care ethic: A dialogue between the thoughts of Joan Tronto and Emmanuel Levinas, Ethical Perspectives: Fournal of the European Ethics Network 13 (1): 33-61.

Engster, D. (2007) The heart of justice: Care ethics and political theory, Oxford: Oxford University Press.

Engster, D. (2018) Care ethics, dependency, and vulnerability, Ethics \& Social Welfare, 13(2), 100.

Fuchs, T. and de Jaegher, H. (2009) Enactive intersubjectivity: Participatory sense-making and mutual incorporation, Phenomenology and the Cognitive Sciences, 8(4), 465-86.

Gilleard, C.J. and Higgs, Paul (2013) Ageing, corporeality and embodiment, New York: Anthem Press.

Gilligan, C. (1982) In a different voice: Psychological theory and women's development, Cambridge: Harvard University Press.

Hamington, M. (2004) Embodied care: Fane Addams, Maurice Merleau-Ponty, feminist ethics, Urbana: University of Illinois Press. 
Hamington, M. (2018) The care ethics moment: international innovations. International Journal of Care and Caring, 2(3), 309-318.

Hegel, G. W. F. (1977 [1807]) Phenomenology of spirit, Oxford: Clarendon Press.

Hekman, S. J. (1995) Moral voices, moral selves: Carol Gilligan and feminist moral theory, University Park: Pennsylvania State University Press.

Held, V. (2006) The ethics of care: Personal, political, and global, New York: Oxford University Press.

Hill, T. and Thomson, G. (2017) Revising social inclusion to take account of care, International Fournal of Care and Caring, 1(2): 175-90.

Honneth, A. (1995) The struggle for recognition: The moral grammar of social conflicts, Cambridge: Polity Press.

Kittay, E. F. (1999) Love's labor. Essays on women, equality, and dependency, New York: Routledge.

Laitinen A., Särkelä, A. and Ikäheimo, H. (2015) Pathologies of recognition - an introduction', Studies in Social and Political Thought, 25:3-24.

Latour, B. and Woolgar, S. (1986) Laboratory life: The construction of scientific facts, Princeton: Princeton University Press.

Latour, B. (2005) Reassembling the social: An introduction to actor-network-theory, New York, Oxford: Oxford University Press.

Levinas, E. (1969) Totality and infinity: An essay on exteriority, Pittsburgh: Duquesne University Press.

Levinas, E. and Nemo, P. (1985) Ethics and infinity, Pittsburgh: Duquesne University Press.

Lupton, D. and Maslen, S. (2017) Telemedicine and the senses: A review, Sociology of Health \& Illness, 39(8), 1557-71.

Løgstrup, K. E. (1997) The ethical demand, Notre Dame: University of Notre Dame Press.

MacKenzie, G., Rogers, W. and Dodds, S. (2013) Vulnerability: New essays in ethics and feminist philosophy. New York: Oxford University Press.

MacKenzie, D. and Wajcman, J. (1999) Introduction to 'The social shaping of technology', Maidenhead: Open University Press.

Miller, S. C. (2005) The ethics of need: Agency, dignity, and obligation, New York: Routledge.

Mol, A. (2002) The body multiple: Ontology in medical practice, Durham: Duke University Press.

Mol, A. (2008) The logic of care: Health and the problem of patient choice, London: Routledge.

Noddings, N. (1984) Caring: A feminine approach to ethics and moral education, Berkeley: University of California Press.

Östlund, B., Olander, E., Jonsson, O. and Frennert, S. (2015) STS-inspired design to meet the challenges of modern aging. Welfare technology as a tool to promote user driven innovations or another way to keep older users hostage?, Technological Forecasting \&્ Social Change, 93: 82-90.

Pols, J. and Willems, D. (2011) Innovation and evaluation: taming and unleashing telecare technology, Sociology of Health E Illness, 33 (3): 484-98.

Roberts, C. and Mort, M. (2009) Reshaping what counts as care: Older people, work and new technologies, ALTER, European Fournal of Disability Research, 3: 138-58.

Robinson, F. (1999) Globalizing care: Ethics, feminist theory, and international relations. Boulder, CO: Westview. 
Stiegler, B. (1998) Technics and time: 1, the fault of Epimetheus, Stanford: Stanford University Press.

Stokke, R. (2017) "Maybe we should talk about it anyway": a qualitative study of understanding expectations and use of an established technology innovation in caring practices, BMC Health Services Research, 17 (1): 657.

Søndergaard Christensen A. M. (2015). Relational views of ethical obligation in Wittgenstein, Lévinas and Løgstrup, Ethical Perspectives, 22(1): 15-38.

Tronto, J. C. (1993) Moral boundaries. A political argument for an ethic of care, New York: Routledge.

Tronto, J. C. (2013) Caring democracy. Markets, equality, and justice, New York: New York University Press.

Turkle, S. (2011) Alone together: Why we expect more from technology and less from each other, Basic Books: New York.

Twigg, Julia (2000) Bathing. The body and community care, London: Routledge.

Van der Heide, L., Willems, C., Spreeuwenberg, M., Rietman, J. and de Witte, L. (2012) Implementation of CareTV in care for the elderly: The effects on feelings of loneliness and safety and future challenges, Technology \& Disability, 24 (4), 283-91.

Verbeek, P. (2006) 'Materializing morality: Design ethics and technological mediation', Science, Technology, \& Human Values, 31(3): 361-80.

Wilshire, D. (1992) The uses of myth, image, and the female body in re-visioning knowledge', in A.M. Jaggar and S.R. Bordo (eds) Gender, body, knowledge: Feminist reconstructions of being and knowing, New Brunswick: Rutgers University Press, pp. 92-114.

Wærness, K. (1984) 'Caring as women's work in the welfare state', in Holter H. (ed) Patriarchy in a welfare society, Oslo: Universitetsforslaget, pp.67-87. 